\title{
Anomalous subcritical crack growth in silica
}

T. Fett, C. Bucharsky, K.G. Schell 


\section{IAM Institute for Applied Materials}

\section{Impressum}

Karlsruher Institut für Technologie (KIT) www.kit.edu

\section{(c) (1) (2)}

This document is licensed under the Creative Commons Attribution - Share Alike 4.0 International License (CC BY-SA 4.0): https://creativecommons.org/licenses/by-sa/4.0/deed.en

2020

ISSN: 2194-1629 


\begin{abstract}
Silica shows the effect of subcritical crack growth in humid environments. Measurements in liquid water show increasing subcritical crack growth velocities when the temperature is increased as was shown by Wiederhorn and Bolz. Since this has been generally found for glasses, this effect is called normal subcritical crack growth.

For measurements on silica in water vapour environment the astonishing effect of decreasing crack-growth rate $v$ at an increased temperature was observed for constant partial water pressure in the humid environment. This surprising result observed in $v-K$ experiments by Suratwala and Steele is called anomalous subcritical crack growth behavior.

In the present report we consider the effects of reduced water solubility at silica surfaces and crack-tip shielding as the reasons for anomalous subcritical crack growth. Three influences were found, namely the water vapour pressure, the temperature-dependent surface solubility of water, and crack-tip shielding.

From our computation, we can conclude that silica shows normal subcritical crack growth, when it is taken into account that the real physical stress intensity factor $K_{\mathrm{I}}$ is used that describes the stresses in the singular crack-tip field, i.e. when $v$-is plotted vs. $K_{\text {tip }}$.
\end{abstract}




\section{Contents}

1 Introduction 1

2 Experimental crack growth results from literature 1

3 Expectation from reaction rate theory 2

4 Effect of vapour pressure 3

5 Effect of water solubility 3

6 Effect of shielding stress intensity factor 6

6.1 Constant shielding 6

$\begin{array}{ll}6.2 \text { Variable shielding } & 7\end{array}$

$\begin{array}{ll}\text { Conclusion } & 11\end{array}$

$\begin{array}{ll}\text { References } & 12\end{array}$ 


\section{Introduction}

Subcritical crack growth behavior of silica is usually presented in form of $v(K)$-curves where $v$ is the crack-growth rate and $K$ the externally applied stress intensity factor. Results are reported as a function of relative humidity and temperature in $[1,2,3]$. They show an increase of subcritical crack growth rates at constant $K$ with increasing temperatures. For silica the astonishing effect of decreasing crack-growth rate $v$ at an increased temperature was observed for constant partial water pressure in the humid environment. This surprising result observed in $v-K$ experiments by Suratwala and Steele [4] is called anomalous subcritical crack growth behavior. In [5] we discussed the apparently incompatible temperature trends qualitatively. In this report quantitative computations will be carried out.

\section{Experimental crack growth results from literature}

In order to discuss anomalous crack growth, some basic results from literature are compiled. In Fig. 1a $v$ - $K$-curves for constant vapour pressure of $p=2100-2200 \mathrm{~Pa}$ are plotted [4]. There is a clear decrease of crack velocity with increasing temperature visible and is the reason for the notation "anomalous subcritical crack growth".
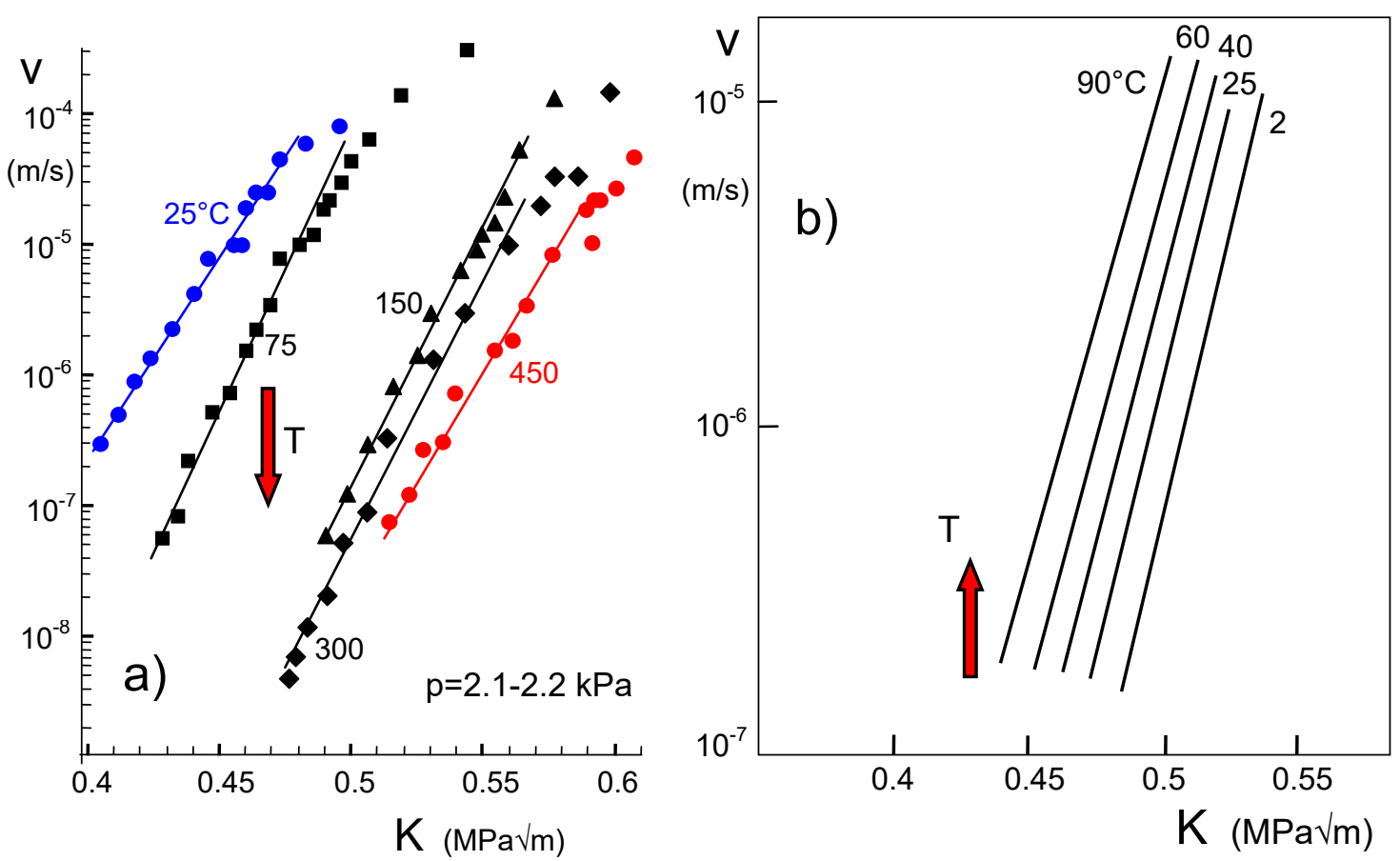

Fig. 1 a) $v$ - $K$-curves for constant vapour pressure of $p=2.1-2.2 \mathrm{kPa}$ by Suratwala and Steele [4], b) $v$ - $K$ curves in liquid water by Wiederhorn and Bolz [1].

Measurements on silica in liquid water were published by Wiederhorn and Bolz [1] as shown in Fig. $1 \mathrm{~b}$ for the temperature region $2^{\circ} \mathrm{C} \leq T \leq 90^{\circ} \mathrm{C}$. From this figure it is evident 
that the crack-growth rates increase with increasing temperature. At first glance, this seems to be in contrast to the results of Suratwala and Steele [4].

In this report it will be shown that the main difference between these contrary results is the fact of strongly different water vapour pressure in the two tests. Whereas in the tests of Fig. 1a the pressure was kept constant at 2.1-2.2 $\mathrm{kPa}$, the saturation pressure varies in the water tests of Fig. $1 \mathrm{~b}$ strongly, namely a factor of $>100\left(0.6 \mathrm{kPa}\right.$ at $2^{\circ} \mathrm{C}$ and $70 \mathrm{kPa}$ at $90^{\circ} \mathrm{C}$ ).

Consequently, the water concentrations at the glass surface and at the crack tip are clearly different. This will be outlined in the following theoretical considerations.

\section{Expectation from reaction rate theory}

In [6] Wiederhorn et al. suggest for the subcritical crack growth rate $v$ as a function of stress intensity factor $K$, and temperature $T$

$$
v=A_{1} C k_{r}(T) \exp \left[\frac{-Q+b K}{R T}\right]
$$

where $C$ is the concentration of molecular water $\left[\mathrm{H}_{2} \mathrm{O}\right], T$ the temperature in ${ }^{\circ} \mathrm{K}, R$ the gas constant, $Q$ the activation energy and $A_{1}$ and $b$ are proportionality constants. In eq.(1) the quantity $k_{\mathrm{r}}(T)$ is the rate coefficient for the single-step reaction showing the temperature dependency

$$
k_{r}(T) \propto T \exp \left[\frac{-\Delta G}{R T}\right]
$$

( $\Delta G=$ free energy of activation). From eqs.(1) and (2) we get with $Q_{1}=Q+\Delta G$

$$
v=A_{2} C T \exp \left[\frac{-Q_{1}+b K}{R T}\right]
$$

Under a water vapour pressure $p$, and the solubility for molecular water at the surface, $C_{1 \mathrm{kPa}}$, the water concentration reads

$$
C=p C_{1 k P a}
$$

and equation (3) results in

$$
v=A_{2} p C_{1 k P a} T \exp \left[\frac{-Q_{1}+b K}{R T}\right]
$$

When evaluating the temperature dependence, it should be noted that both pressure and solubility also vary with temperature. These influencing factors will be considered here. 


\section{Effect of vapour pressure}

The crack-growth rates from Fig. $1 \mathrm{~b}$ are transformed by eq.(3a) to a constant vapour pressure of $p=3.2 \mathrm{kPa}$ (saturation pressure at $25^{\circ} \mathrm{C}$ ), Fig. 2, exhibiting clearly the same temperature trend as found by Suratwala and Steele [4]. It should be noted that in the plot only the ordinate has been reduced to constant pressure and the abscissa values remain unaffected. From this plot one could claim that even in liquid water anomalous subcritical crack growth is present.

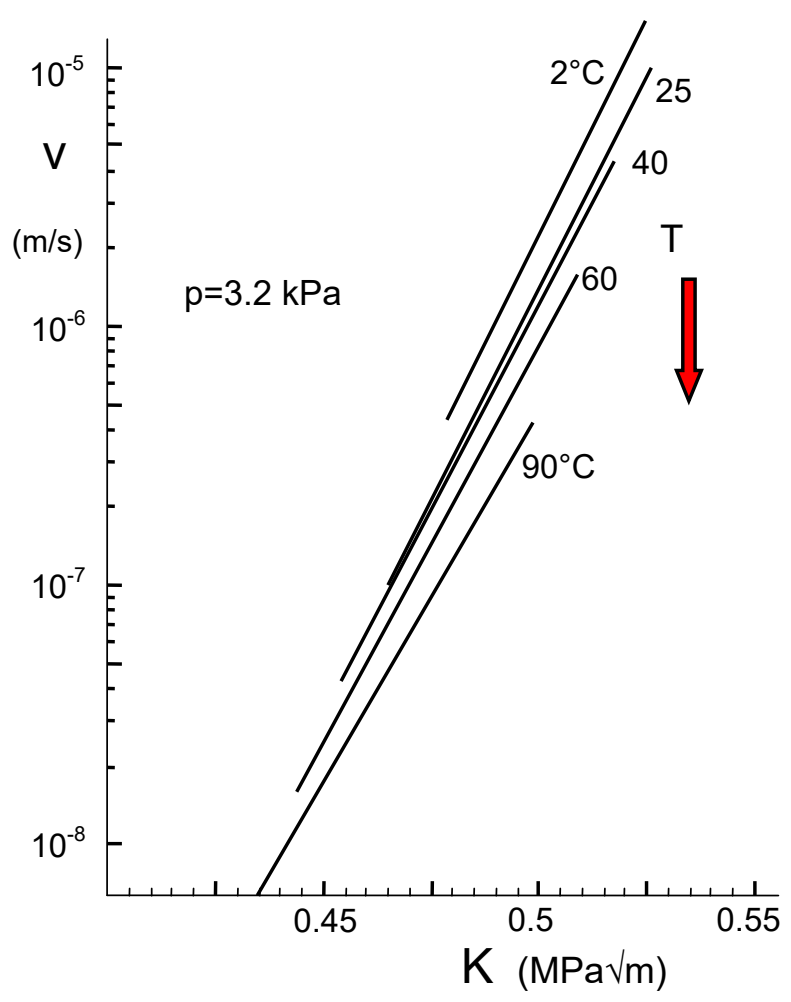

Fig. $2 v$ - $K$-curves in liquid water by Wiederhorn and Bolz [1], transformed to a common saturation pressure of $3.2 \mathrm{kPa}$ (saturation pressure at $25^{\circ} \mathrm{C}$ ) according to eq.(3a).

\section{Effect of water solubility}

Since the $v$ - $K$-curves should depend on the water concentrations at the glass surface, eq.(1), results of water concentrations are shown in Fig. 3a as a function of temperature. These data represent the concentrations of the molecular and hydroxyl water species obtained from measurements by Zouine et al. [7] under saturation pressure. Silica reacts with the silica network according to

$$
\equiv \mathrm{Si}-\mathrm{O}-\mathrm{Si} \equiv+\mathrm{H}_{2} \mathrm{O} \leftrightarrow \equiv \mathrm{SiOH}+\mathrm{HOSi} \equiv
$$

with the concentration of the hydroxyl $S=[\equiv \mathrm{SiOH}]$ and that of the molecular water $C$ $=\left[\mathrm{H}_{2} \mathrm{O}\right]$. In molar units, the total water concentration $C_{\mathrm{w}}$ is given by 


$$
C_{w}=C+\frac{1}{2} S=C\left(1+\frac{1}{2} k\right)
$$

where $k$ is the equilibrium constant describing the ratio of $k=S / C$.
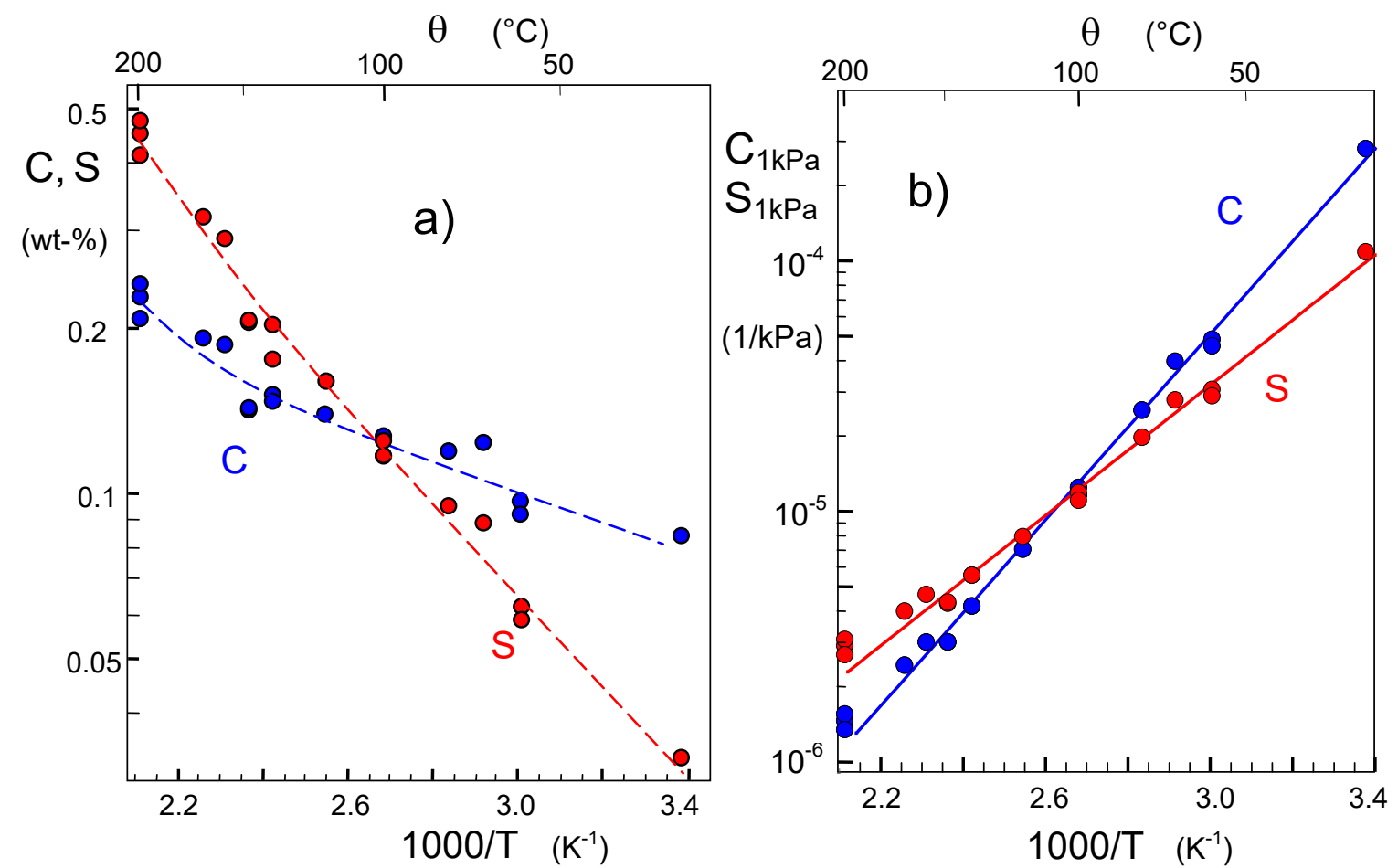

Fig. 3 a) Solubility of water species at silica surfaces under saturation pressure derived from data by Zouine et al. [7], b) water concentrations normalized on the saturation pressure.

A relation for the ratio $S / C$ of the two water species, where $S$ stands for the hydroxyl concentration and $C$ for the concentration of molecular water, was given by Wiederhorn et al. [8]. For the temperature range of $90^{\circ} \mathrm{C} \leq \theta \leq 350^{\circ} \mathrm{C}\left(T=273^{\circ}+\theta\right)$, the data are fitted by the straight line

$$
k=\frac{S}{C}=A \exp \left(-\frac{Q}{R T}\right)
$$

( $A=32.3$ and $Q=10.75 \mathrm{~kJ} / \mathrm{mol}$ ). Equations (6) and (7) result in

$$
\begin{aligned}
& C=\frac{C_{w}}{1+\frac{1}{2} k}, \\
& S=\frac{C_{w}}{\left(\frac{1}{2}+\frac{1}{k}\right)}
\end{aligned}
$$

and in mass units 


$$
S=\frac{17}{18} \frac{C_{w}}{\left(\frac{1}{2}+\frac{1}{k}\right)}
$$

(the ratio 17/18 reflects the different mole masses of water and hydroxyl).

Figure 3a shows the concentrations of the two water species under saturation pressure. In Fig. $3 b$ the water concentrations $S \propto p$ and $C \propto p$ are normalized on the water vapour pressure of $p=1 \mathrm{kPa}$. The straight lines can be expressed by

$$
\Rightarrow C_{1 \mathrm{kPa}} \cong \exp \left[-22.79+\frac{35.84 \mathrm{~kJ} / \mathrm{mol}}{R T}\right]
$$

and

$$
S_{1 \mathrm{kPa}} \cong \exp \left[-19.41+\frac{25.09 \mathrm{~kJ} / \mathrm{mol}}{R T}\right]
$$

The crack velocities of Fig. 1 are plotted in Fig. 4 in the normalized representation as $v /(C \times T)$ vs. applied $K$ for the partial water vapour pressure of $p=3.2 \mathrm{kPa}$ (i.e. the saturation pressure at $25^{\circ} \mathrm{C}$ ). It can be seen that the temperature tendency of Fig. $4 \mathrm{~b}$ is now again as normal crack-growth behaviour. This makes clear that even for constant vapour pressure the anomalous crack-growth behaviour is at least partially caused by the reduced surface water concentration with increasing temperature.
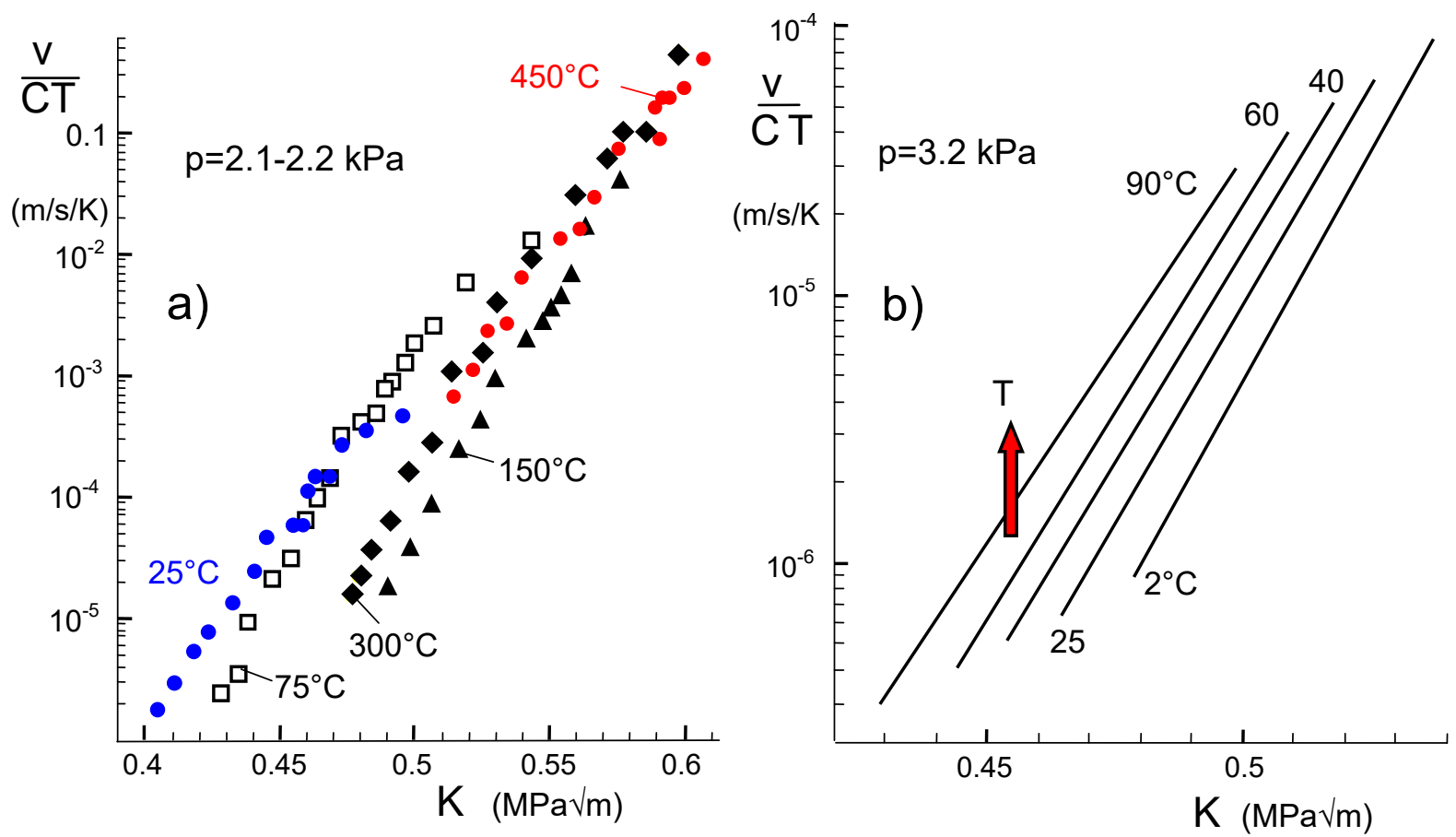

Fig. 4 Crack-growth rates normalized on the molecular water concentration and temperature $T$, a) data from Fig. 1a, b) data from Fig. 1b. 


\section{Effect of shielding stress intensity factor}

\subsection{Constant shielding}

In our opinion, at least a part of the observed trend is caused by crack-tip shielding. In the preceding considerations we implicitly identified the externally applied stress intensity factor $K_{\text {appl }}$ with the $K$-value acting at the crack tip, $K_{\text {tip }}$. It was early outlined in $[9,10]$ that a shielding stress intensity factor must develop as a consequence of volume increase by the hydroxyl generation (for references see e.g. [11]). Computations by McMeeking and Evans [12] result in a shielding stress intensity factor for a grown crack which is surrounded by a zone of thickness $\omega$ undergoing a volume strain $\varepsilon_{\mathrm{v}}$

$$
K_{s h}=-\psi \frac{\varepsilon_{v} E}{1-v} \sqrt{\omega}
$$

with $\psi=0.22$ [12]. $E$ is Young's modulus and $v$ Poisson's ratio. In case of glass, $\omega$ is the thickness of the water diffusion zone around the crack tip.

It has been shown in [13] that water-induced swelling at crack tips generates an intrinsic stress intensity factor $K_{\mathrm{sh}}<0$ that shields a crack from an externally applied loading $K_{\text {appl }}$ so that the stress intensity factor $K_{\text {tip }}$ at the crack tip is reduced. The effective stress intensity factor acting at the crack tip, $K_{\text {tip }}$, represents the singular stress field at the tip. From the principle of superposition, $K_{\text {tip }}$ is given by

$$
K_{\text {tip }}=K_{a p p l}+K_{s h}, \quad K_{s h}<0 \quad \Rightarrow K_{t i p}<K_{a p p l}
$$

The effect of the shielding stress intensity factor on the $v-K$-curves was outlined in [13]. The volume strain $\varepsilon_{\mathrm{v}}$ is related to the hydroxyl concentration $S$ by the proportionality

$$
\varepsilon_{v}=\kappa S
$$

with $\kappa \cong 0.97$ at least at low concentrations $S$ as could be concluded from the density decrease reported by Shelby [11]. Consequently, it holds

$$
K_{s h}=-\psi \frac{\kappa S E}{1-v} \sqrt{\omega}
$$

The hydroxyl concentration $S$ in the crack-tip stress field is thermally activated as eq.(7) implies. Since also the diffusivity is thermally activated, the water diffusion zone, $\omega=\mathrm{f}(\sqrt{ } D t)$, increases with temperature due to the increase of the diffusivity. Consequently, the shielding stress intensity factor $K_{\mathrm{sh}}=\mathrm{f}(S, \omega)$ must become stronger with increasing temperature via an Arrhenius equation.

When in a subcritical crack growth test the shielding stress intensity factor equals $-K_{\text {appl }}$, the total stress intensity factor $K_{\text {tip }}$ disappears followed by abruptly decreasing crack rates, i.e. the threshold values $K_{\text {th }}$ of the $v-K$ curve is reached. This is equivalent to 


$$
K_{t h}=-K_{s h}
$$

Threshold values for silica were evaluated by Sglavo et al. [14] on the basis of literature results, $[15,16]$. The threshold stress intensity factor as a function of temperature $\theta$ was described by an Arrhenius temperature dependency

$$
K_{t h} \cong K_{t h, 0} \exp \left[\frac{-q}{R T}\right]
$$

with $K_{\text {th }, 0}=0.638 \mathrm{MPa} \sqrt{\mathrm{m}}$ and $q=1.83 \mathrm{~kJ} / \mathrm{mol}$. Equations (15) and (16) make it possible to calculate the shielding stress intensity factor $K_{\mathrm{sh}}$ and via eq.(13) the total stress intensity factor $K_{\text {tip }}$ acting at the crack tip. This value is responsible for the crack-tip stresses and subcritical crack growth rates.

Finally, Fig. 5 gives the curves of Fig. 4 vs. the difference $K_{\text {appl }}-K_{\text {th. }}$. Under the assumption that $K_{\text {sh }} \neq \mathrm{f}\left(K_{\text {appl }}\right)$, the curves in Fig. 5 agree with the $v-K_{\text {tip }}$ curves.

The diagrams of Fig. 5 show that, for the same water concentration, plotting against the stress intensity factor $K_{\text {tip }}$ (actually prevailing at the crack tip) leads to normal subcritical crack growth in both cases, namely increasing crack rates with increasing temperature.
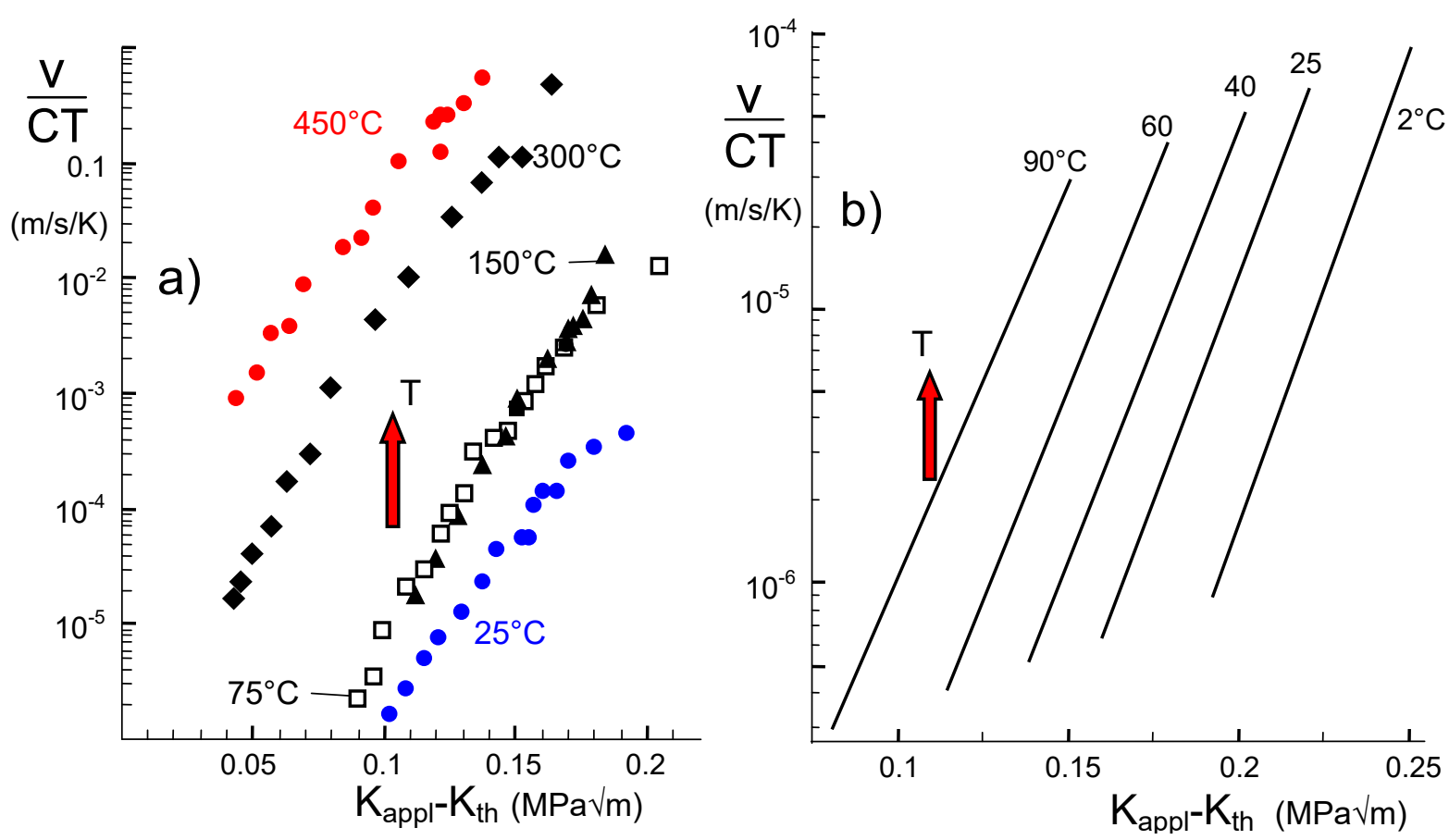

Fig. 5 Crack-growth rates from Figs.(4a) and (4b) plotted vs. stress intensity factor $K_{\text {appl }}-K_{\text {th }}$.

\subsection{Variable shielding}

Deviations from the assumption of a constant shielding stress intensity factor $K_{\mathrm{sh}}$ have to be expexted. With increasing crack-growth rates the time for the water entrance via diffusion decreases and, consequently, the zone height $\omega$ in eq.(12b) becomes smaller. This yields in decreasing shielding stress intensity factor $K_{\mathrm{sh}}$ with increasing $v$ or in- 
creasing load. A computation of $K_{\mathrm{sh}}\left(K_{\mathrm{appl}}, T\right)$ was performed in [5] resulting in rather complicated equations and should not be duplicated here. An approximate method may be suggested to estimate $K_{\text {sh }}$ or, equivalently, $K_{\text {tip }}$ as a function of $K_{\text {appl }}$. For this purpose two basic results may be used.

1) According to the derivation by Wiederhorn, the stress intensity factor $K$ in eq.(1) is the physically active total stress intensity factor $K_{\text {tip }}$ governing the singular crack-tip stress field. In a $\lg (v)-K_{\text {tip }}$-plot this must result in a straight line:

$$
\log v \propto b K_{t i p}
$$

2) As the subcritical crack growth curve for silica in liquid water at $25^{\circ} \mathrm{C}$ (Wiederhorn and Bolz [1]) shows, the crack velocity as a function of the applied stress intensity factor is also very straight over a large region of crack rates, Fig. 6a. This can be written as

$$
\log v \propto b K_{a p p l}
$$

Equation (13) requires that even the shielding stress intensity factor must fulfil a similar relation, namely,

$$
\log v \propto b K_{s h}
$$

If $K_{\text {sh }}$ depends on $v$ there must occur an intersection of the straigt lines according to (17a) and (17b).

3) When $K_{\text {tip }}$ reaches fracture toughness $K_{\text {Ic }}$, the crack extension becomes very fast. Velocities in the order of sound velocity occur. Consequently, diffusion effects of surface water into the crack-tip region will disappear as well as the related shielding term, i.e. $K_{\mathrm{sh}}\left(K_{\mathrm{Ic}}\right) \rightarrow 0$. This situation is indicated by the circle in Fig. $6 \mathrm{~b}$.

From the points 1)-3) we obtain in terms of $K_{\text {tip }}$

$$
K_{s h} \approx-\left(1-\frac{K_{t i p}}{K_{I c}}\right) K_{t h}
$$

and in terms of $K_{\text {appl }}$

$$
\begin{gathered}
K_{s h} \approx-\frac{K_{I c}-K_{a p p l}}{K_{I c}-K_{t h}} K_{t h} \\
K_{t i p} \approx \frac{K_{a p p l}-K_{t h}}{K_{I c}-K_{t h}} K_{I c}
\end{gathered}
$$

Figure 7 represents the $v$ - $K_{\text {tip }}$ results for the data in Figs. $4 \mathrm{a}$ and $4 \mathrm{~b}$. Even from these plots normal subcritical crack growth can be stated. With increasing temperature the 
crack growth rates for identical water concentrations at the glass surfaces increase, too. This holds for tests in liquid water as well as tests in humid air.
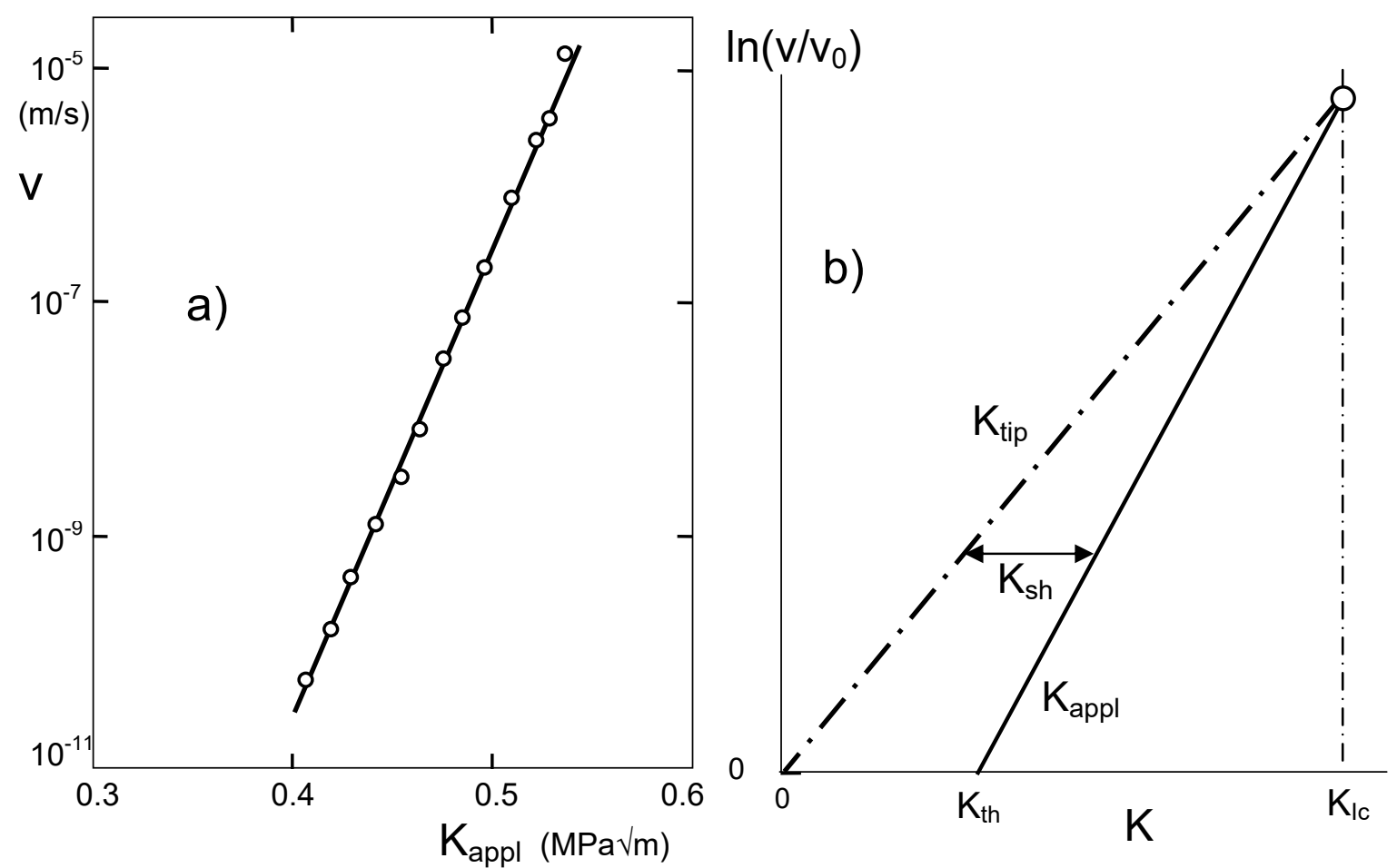

Fig. 6 a) v-K curve of silica in liquid water by Wiederhorn and Bolz [1] at a temperature of $25^{\circ} \mathrm{C}, \mathrm{b}$ ) suggestion for the estimation of the $v$ - $K_{\text {tip }}$ curve.
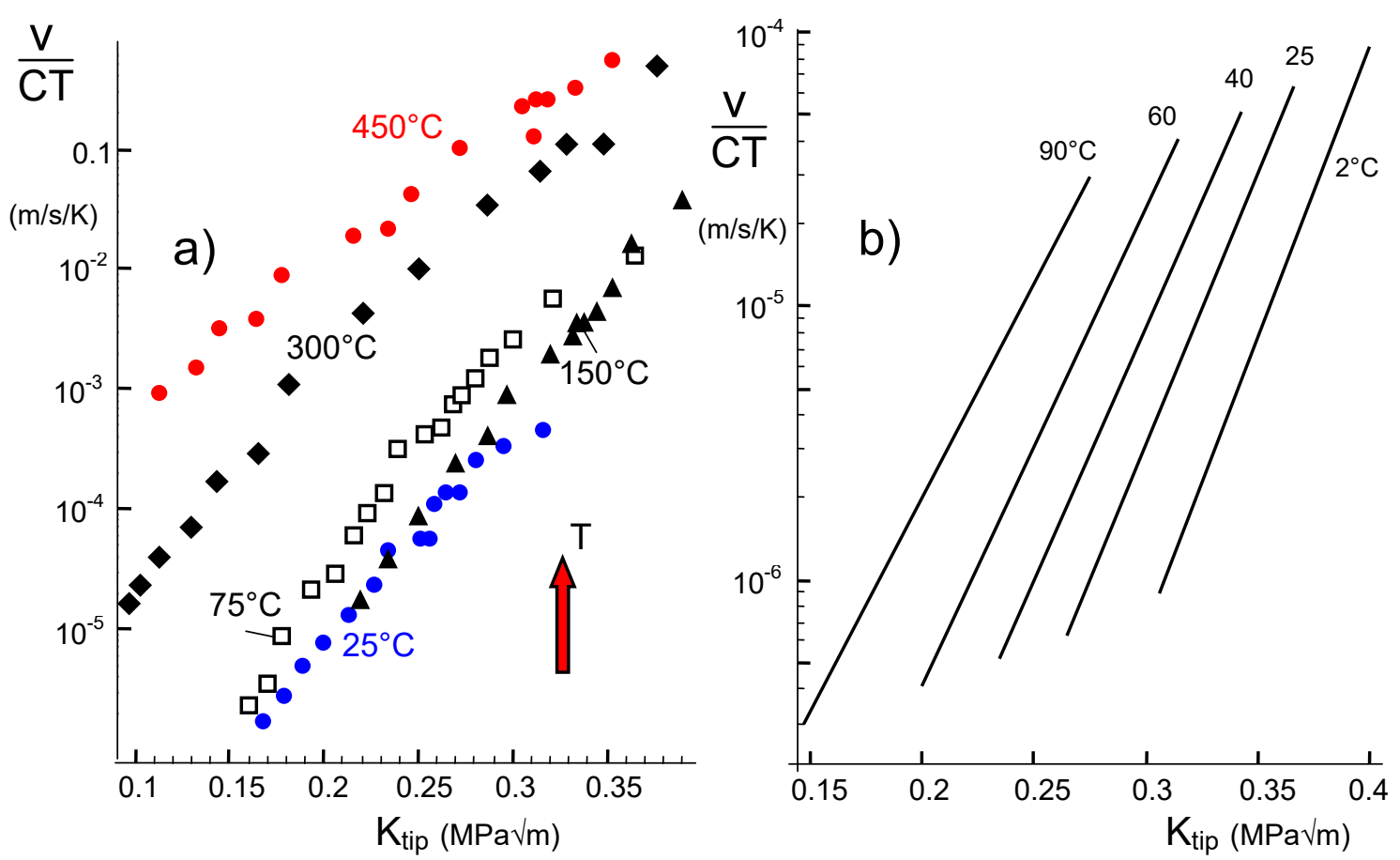

Fig. 7 Crack-growth rates from Figs. $4 \mathrm{a}$ and $4 \mathrm{~b}$ plotted vs. crack-tip stress intensity factor $K_{\text {tip }}$. 
Finally, Fig. 8 shows the stress intensity factor $K_{\text {tip }}$ necessary for reaching a constant normalized crack velocity. There seems to exist a discontinuity in Fig. 8 between $75^{\circ} \mathrm{C}$ and $150^{\circ} \mathrm{C}$. A possible reason might be capillary condensation at crack tips. A zone of liquid water can be identified at a crack tip at low temperatures in humid air as had been shown by Ciccotti et al. [17], Grimaldi et al. [18], and Pallares et al [19]. At the high temperatures this is no longer possible. So one would expect a discontinuity for tests in "water" to tests in humid air.

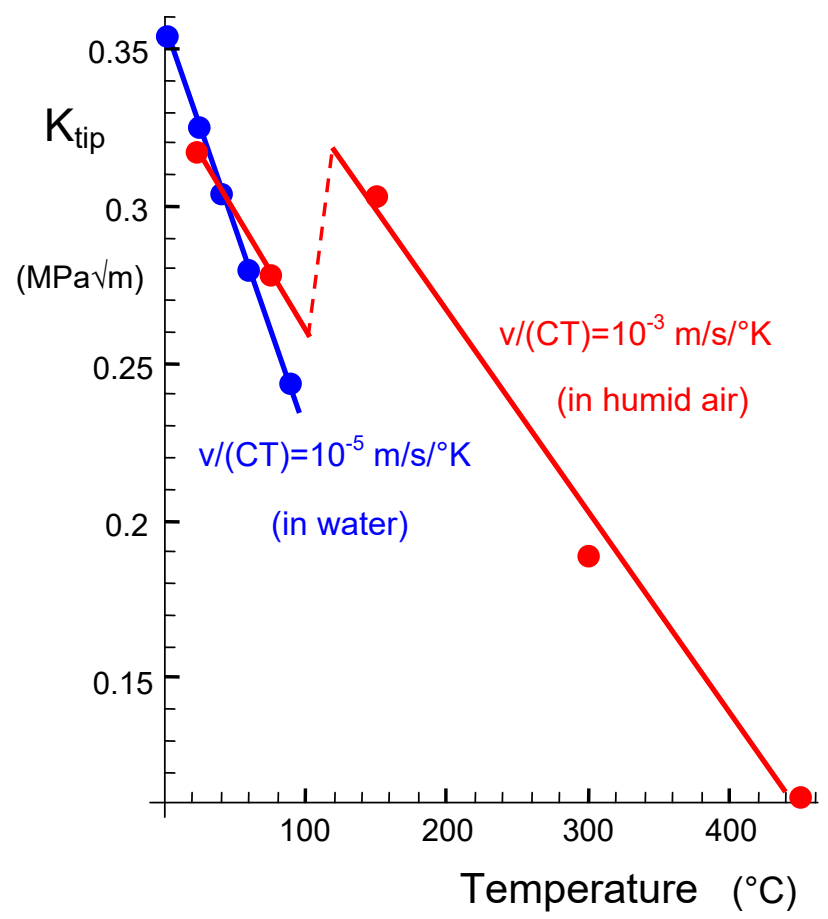

Fig. 8 Stress intensity factors $K_{\text {tip }}$ for constant normalized subcritical crack growth rates as a function of temperature, red: results in humid air by Suratwala and Steele [4], blue: results in liquid water by Wiederhorn and Bolz [1].

From the subcritical crack growth rates of Fig. 7 the slopes, $B$, were determined. Additionally the parameter $B$ for a representation by $\log (v) \propto B K_{\text {appl }}$ is introduced for the data by Wiederhorn and Bolz [1]. For the slopes $B$ one would expect from the theoretical analysis by Wiederhorn et al. [6] according to eq.(1)

$$
\log v \propto B K_{t i p}, \quad B=\frac{b}{R T}
$$

i.e. a decrease of $B$ with increasing reciprocal absolute temperature $T$. The result is illustrated in Fig. 9a where the parameter $B$ from eq.(21) is plotted. The values of $B$ increase with decreasing temperature. This applies to all results with the exception of the data by Suratwala and Steele [4] for temperatures below $150^{\circ} \mathrm{C}$, see also the jump in Fig. 8. Below this temperature, the effect seems to be slightly reversed. In Fig. $9 \mathrm{~b}$ the parameter $b$ defined in eq.(1) is shown. 

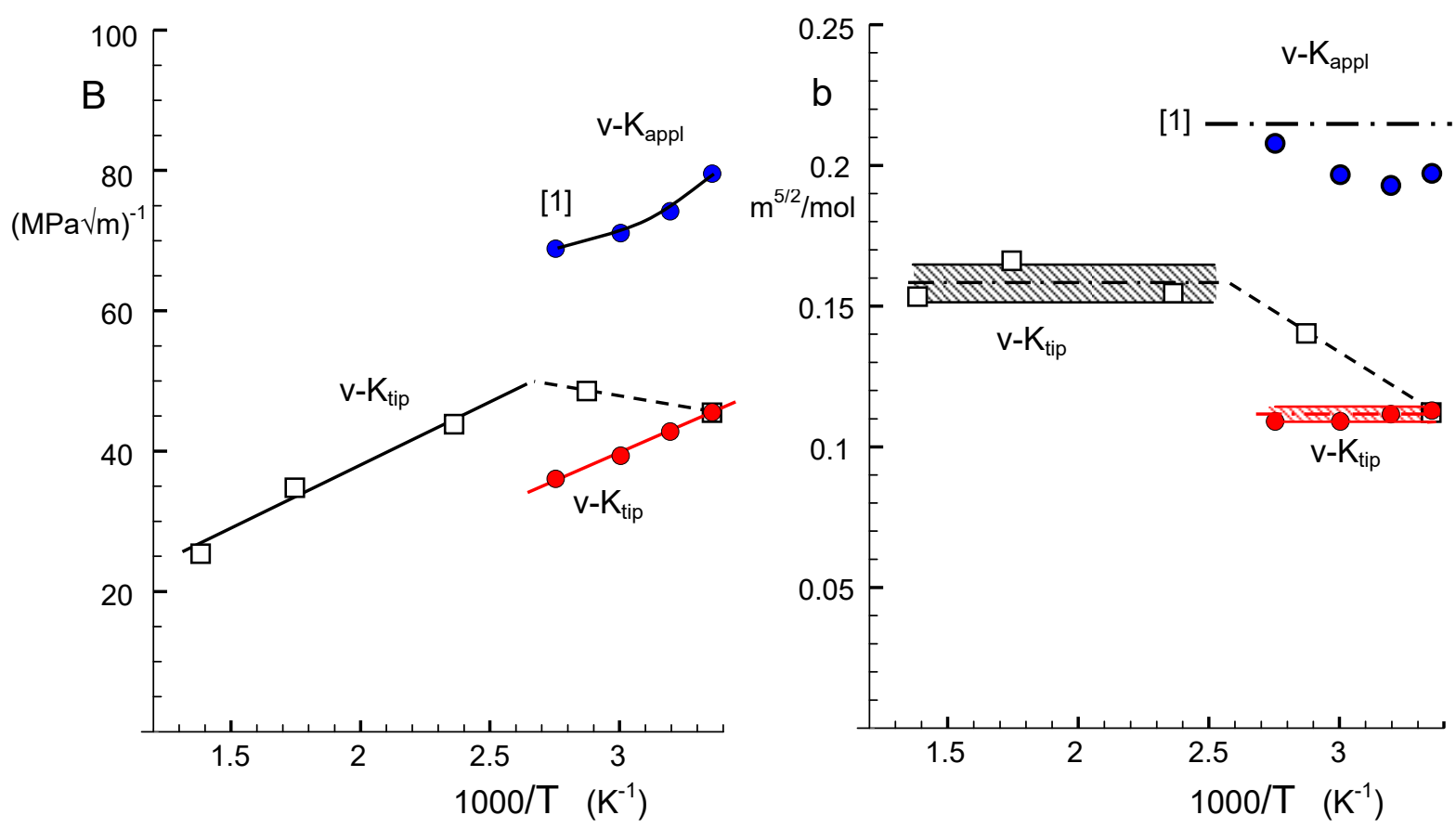

Fig. 9 a) Slopes $B$ of subcritical crack growth curves $v\left(K_{\text {tip }}\right)$ as a function of temperature, b) parameter $b=B \times R T$, hatched area: scatter ranges.

The parameter $b$ is for the representation via $K_{\text {tip }}$ a constant. This holds for the data from [1] and the data above $\approx 100^{\circ} \mathrm{C}$ from [4] but decreases for lower temperatures as is included in Fig. $9 \mathrm{~b}$ as the dashed line. The representation by (21) yields (Standard Deviations in brackets)

$$
b=0.112[0.0017]\left(\mathrm{m}^{5 / 2} / \mathrm{mol}\right) \text { for [1] }
$$

and

$$
b=0.158[0.0073]\left(\mathrm{m}^{5 / 2} / \mathrm{mol}\right) \text { for }[4] \text { and } \geq 150^{\circ} \mathrm{C}
$$

\section{Conclusion:}

We studied subcritical crack growth results measured by Suratwala and Steele [4] in water vapour and by Wiederhorn and Bolz [1] measured in liquid water under saturation pressure. From the results shown before, the anomalous subcritical crack growth in the experiments by Suratwala and Steele [4] is a consequence of the decreasing surface water solubility with increasing temperature and the plotting against the applied stress intensity factor $K_{\text {appl }}$ instead of the physically acting value $K_{\text {tip }}$ that governs the singular stress field at crack tips. With other words: Subcritical crack growth in silica is normal since for constant water concentration at crack tips the crack-growth rate at constant $K_{\text {tip }}$, increases with increasing temperature. 
It is also noteworthy that if the temperature dependence of the saturation pressure is eliminated exclusively in the tests in liquid water [1], anomalous crack growth behaviour would appear (Fig. 2).

This suggests that the representation of $v$ - $K$-curves for constant pressure instead of constant water concentration in the glass and by plotting the crack-growth rates vs. the applied stress intensity factor (instead of the physically relevant crack-tip stress intensity factor, $\left.K_{\text {tip }}\right)$ is responsible for the anomalous behaviour of silica.

\section{References}

1. S.M. Wiederhorn and L.H. Bolz, "Stress Corrosion and Static Fatigue of Glass," J. Am. Ceram. Soc. 53[10] 543-548 (1970).

2. S.M. Wiederhorn, H. Johnson, A.M. Diness and A.H. Heuer, "Fracture of Glass in Vacuum," J. Am. Ceram. Soc. 57 [8] 336-341 (1974).

3 Wiederhorn, S.M., Influence of water vapour on crack propagation in soda-lime glass, J. Am. Ceram. Soc. 50(1967), 407-414.

4 T.I. Suratwala and R.A. Steele, "Anomalous temperature dependence of sub-critical crack growth in silica glass," J. Non-Crystalline Sol. 316 174-182 (2003).

5 T. Fett, C. Bucharsky, G. Schell, Anomalous temperature behaviour of subcritical crack growth in silica, 131, 2019, ISSN: 2194-1629, Karlsruhe, KIT

6 S.M. Wiederhorn, E.R. Fuller, R. Thomson, Micromechanisms of crack growth in ceramics and glasses in corrosive environments, Metal Science, Aug-Sept (1980), 450-458.

7 A. Zouine, O. Dersch, G. Walter and F. Rauch, "Diffusivity and solubility of water in silica glass in the temperature range $23-200^{\circ} \mathrm{C}$," Phys. Chem. Glass: Eur. J. Glass Sci and Tech. Pt. $B, 48$ [2] (2007), 85-91.

8 S. M. Wiederhorn, F. Yi, D. LaVan, T. Fett, M.J. Hoffmann, Volume Expansion caused by Water Penetration into Silica Glass, J. Am. Ceram. Soc. 98 (2015), 78-87.

9 S. M. Wiederhorn, T. Fett, G. Rizzi, S. Fünfschilling, M.J. Hoffmann, J.-P. Guin, Effect of Water Penetration on the Strength and Toughness of Silica Glass, J. Am. Ceram. Soc. 94 [S1] (2011), 196-S203.

10 S.M. Wiederhorn, T. Fett, G. Rizzi, M. Hoffmann, J.-P. Guin, "Water Penetration - its Effect on the Strength and Toughness of Silica Glass," Met. Mater. Trans. A, 44(2013) [3], $1164-1174$.

11 Shelby, J.E., "Density of vitreous silica,” J. Non-Cryst. 349 (2004), 331-336.

12 McMeeking, R.M., Evans, A.G. Mechanics of transformation-toughening in brittle materials, J. Am. Ceram. Soc. 65(1982), 242-246.

13 Wiederhorn, S.M., Fett, T., Rizzi, G., Hoffmann, M.J., Guin, J.-P., The Effect of Water Penetration on Crack Growth in Silica Glass, Engng. Fract. Mech., 100 (2013), 3-16. 
14 V. Sglavo, T. Fett, K.G. Schell, M.J. Hoffmann, S.M. Wiederhorn, $v$ - $K$-data for silica from interrupted lifetime measurements, 144, 2020, ISSN: 2194-1629, Karlsruhe, KIT.

15 V.M. Sglavo and D.J. Green, "Fatigue limit in fused silica,” J. Eur. Ceram. Soc. 21 (2001) 561-567.

16 J. S. Aaldenberg, P. J. Lezzi, Measurement of the silica glass fatigue limit, J. Am. Ceram. Soc., 103(2020), 3097-103.

17 M. Ciccotti, M. George, V. Ranieri, L. Wondraczek, and C. Marliere, Dynamic Condensation of Water at Crack Tips in Fused Silica Glass, J. Non Cryst. Solids, 354 [2-9] 564-8 (2008).

18 A. Grimaldi, M. George, G. Pallares, C. Marniere, M. Ciccotti, The crack tip: A nanolab for studying confined liquids, Phys. Rev. Letters, 100, 165505 (2008).

19 G. Pallares, A. Grimaldi, M. George, L. Ponson, M. Ciccotti, Quantitative analysis of crack closure driven by Laplace pressure in silica glass, J. Am. Ceram. Soc. 94(2011), 26132618. 
KIT Scientific Working Papers

ISSN 2194-1629

www'kit.edu 